\title{
De aparato de captura a dispositivo académico. El currículum vitae en la universidad
}

\author{
From capture machine to academic device. The curriculum vitae in the university
}

José Luis Anta Félez

Área de Antropología Social. Universidad de Jaén (España)

jlanta@ujaen.es

\begin{abstract}
RESUMEN

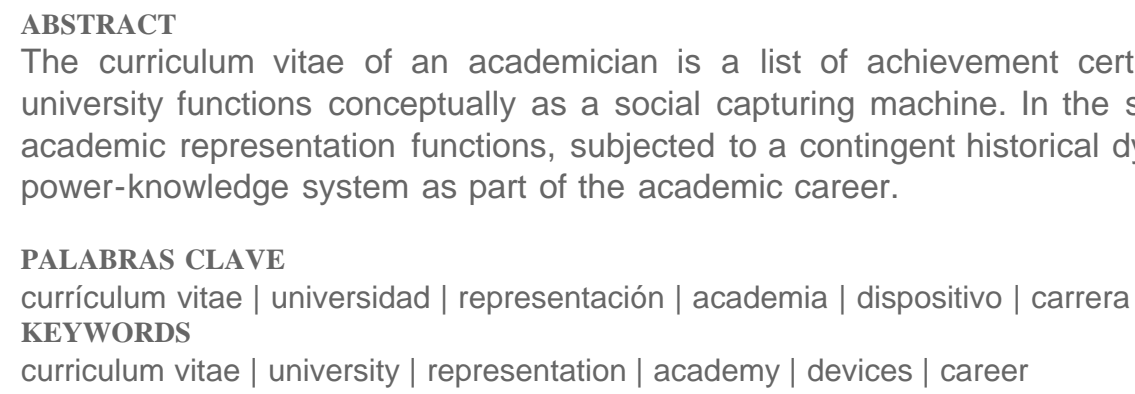
power-knowledge system as part of the academic career.

El currículum vitae de un académico es una serie de papeles que muestran los logros certificados en forma estándar. De ahí que sea una muestra de cómo funciona la universidad conceptualmente como un aparato de captura social. De la misma manera en este artículo me planteo la idea de cómo funciona la representación de los académicos, sujetos de una dinámica histórica contingente y cómo son los dispositivos que el sistema Saber-Poder plantea como parte de la carrera académica.

The curriculum vitae of an academician is a list of achievement certificates in standard form. Thus it exemplifies how the university functions conceptually as a social capturing machine. In the same way, in this study, I consider the idea of how the academic representation functions, subjected to a contingent historical dynamic, and what sorts of devices are proposed by the

\section{Un lugar llamado universidad}

Podría pensarse que existe un algo físico que se llama universidad. De hecho, las universidades tienen logos y escudos, bibliotecas, estudiantes y profesores que dicen ser universitarios. Hay edificios, departamentos, libros y revistas que viven bajo el amparo de lo que se denomina universidad. Todo apunta hacia la idea de que todo ello forma parte de lo universitario: de aquello que pertenece a un ser ontológico universitario. Pero, por otro lado, cuando un observador ajeno comienza a realizar algún tipo de análisis de aquello que se considera como universidad se le diluye el objeto en un discurso que corre entre lo cotidiano y lo retórico, entre lo peripatético y lo miserable. Es como si lo universitario fuera una amalgama de hechos (acciones encadenadas) que, también en apariencia, tienden a segmentarizarse. ¿Qué tipo de relación mantiene a esos segmentos unidos para que todos ellos se consideren incluidos en la denominada universidad? ¿Qué tienen en común, universitariamente, las tesis doctorales y la enseñanza, los departamentos de derecho financiero y la cafetería? Preguntas como éstas y de este talante han sido contestadas de forma lineal, mecanicista y funcional desde hace siglos, sin que hayan servido de gran cosa, pues, de hecho, las preguntas siguen ahí. Seguramente ahora tampoco estamos en disposición de encontrar respuestas. No importa. Lo interesante de todo ello es que por fin, liberados del yugo de los -ismos, podemos encontrar cierto sentido a las preguntas. El resto, quizás, no le interese a nadie. $Y$ aunque este trabajo se basa en mi propia experiencia, en un breve e intenso trabajo de campo en la Universidad de Jaén y en las realidades que a diario nos invaden he acudido, también, a un ciertas 
novelas que se desarrollan en contextos universitarios (1), en especial a la prolífera obra de David Logde, Tom Sharpe, Kingsley Amis, Malcom Bradbury o James Hynes, que nos han dado páginas que de una manera trágico-cómica están llenas de la desesperanza, dolor, mediocridad, incomprensión y moralina que corre por el actual sistema universitario (2).

En este trabajo me planteo, consecuentemente, reflexiones sobre qué es eso de la universidad -dando por hecho que exista algo genérico que responda a esa denominación-, seguramente, para llegar a una doble conclusión: por un lado, que la vida interna, cotidiana, de la universidad es una enorme red de miserias "personales", en busca de ejercicios sociales de autoridad y, por otro, que lo universitario es un simple ejercicio de voluntad, de fuerza y poder. Pero no lo he hecho desde una maquinaria trabando en vacío, sino desde uno de los elementos clave aunque sobrentendido: el currículum vitae. Aunque hoy el discurso de "la universidad en crisis" no es dominante, tal cual lo fue, sin ir más lejos, a finales de la década de los 60 y principios de los 70, hay una cierta idea generalizada de que la universidad, sea lo que sea, no es una máquina que funcione satisfactoriamente. Ni los más adelantados sistemas de distribución del poder, implementado por políticas "democráticas" han dejado satisfechos a todos aquéllos que se autodenominan universitarios. No es mi intención retomar el viejo debate de "la crisis de". Muy por el contrario, de lo que se trata es de observar esa amalgama que une segmentos, esas ideas que transversalmente permiten a grupos heterogéneos unificarse en un todo llamado universidad. Genial.

Pero el tema no se agota ahí. De hecho, habría que diferenciar entre "la crisis de la universidad" y "la universidad en crisis". Y aquí el problema es que la segunda opción ha eclipsado el debate de la primera. El punto es que la universidad que ha servido de objeto de la mirada de este trabajo no está en crisis, muy por el contrario, y, sin embargo, el modelo de universidad sí lo está, o, más bien, lo sigue estando. Así, pues, ¿cómo se resuelve esta aparente paradoja?, ¿cuál es el contenido y forma de los discursos universitarios?, ¿cómo negocian y toman decisiones los actores universitarios? Estas y otras preguntas parecidas se encuentran en la raíz de este trabajo. No se trata, aunque así lo parezca, de desligar la universidad de lo universitario, sino de encontrar los puntos concretos en que ciertas ideas se plasman en realidades concretas. Por múltiples motivos, ciertas formas concretas de vivir el pensamiento, de amalgamas para segmentos transversalizados, se dan con especial virulencia en unas instituciones más que en otras, y el caso de la universidad, quizás también ocurre con el hospital y la cárcel -en definitiva, cuarteles-, es especialmente ejemplificador. Simplemente porque ahí confluyen diversas realidades políticas, sociales, económicas, individuales, históricas y, a veces también, científicas y disciplinarias.

La universidad es una institución. Obvio. Y, consecuentemente, una idea, que cronológicamente es relativamente reciente. Puede que los edificios, el nombre, algunos individuos que por ella han pasado tengan algunos centenares de años; pero la idea que la conforma como una institución actual es aún joven. Es más, cualquier intento de hacer una historia de la universidad choca frontalmente con su propia novedad, cualquier historia de esta institución es una "historia" del futuro que planteaba en un contexto social de pasado. La universidad, al amalgamar los conceptos básicos de la revolución burguesa libertad, justicia, democracia, conocimiento, universalidad...-, se plantea siempre como un ejercicio de futuro, una especie de utopía en la tierra: un constante simulacro cultural en movimiento hacia la virtualidad. $Y$ este es el contexto de nuestras reflexiones, un lugar difícil y problematizado que no revela fácilmente las reglas con las que juega (3).

Nadie puede dudar que el currículum vitae se entiende como un "currículum normalizado" y que, como tal, tiene algo de inquietante. No sólo porque son dos vocablos difíciles y generalistas, sino porque, sobre todo, juntos forman un cuerpo que nos hace sospechar que seguro ni se trata de un currículum "normal", ni mucho menos de lo normal que es tener un currículum. Sin embargo, las universidades, ministerios, secretarías varias y consejerías con poderes transferidos se empeñan en pedir un "currículum normalizado" cada vez que un académico se pone en comunicación con ellos para pedir, solicitar y/o rogar una ayuda, una beca, un puesto de trabajo o uno de esos proyectos que no se sabe que itinerario tiene que ser rellenado y a la postre mostrado. El currículum normalizado es, así, como esas novenas que hacían algunas abuelas: es una obligación voluntarista que tiene un ritmo de letanía y sirve para saber que uno sigue vivo socialmente gracias a la capacidad del ir y venir a la iglesia. Cuando no había ordenadores con procesadores de texto y se dependía de la máquina de escribir y ahora que los hay por 
lo mismo, el currículum tiene desde un punto de vista académico los mismos ítems (4). Y éste es normalizado, quiero creer más allá de su planteamiento controlador y disciplinador, para evitar las pequeñas y posibles variaciones de estilo y gusto de cada cual. Esos ítems (datos personales, vida académica y producción "científica") son realmente una medida que trata de mostrar más el qué sobre el por qué, el dónde sobre el cómo, y el quién por encima del con quién. En definitiva, son una relación de elementos que tienen más de lista normalizadora que de currículum vitae.

Claro que un currículum hay que saber leerlo, en su sentido de decodificación, de hecho, se pude afirmar que las publicaciones reseñadas son generalmente indicaciones de los por qué y de los cómo. Pero son explicaciones deductivas que suponen que el lector del currículum tiene las claves de su lectura. No es que esté demasiado de acuerdo con la simplista teoría de la comunicación estructuralista, pero obviamente, por dar una guía de lectura, mi argumento para este breve trabajo de reflexión es que el currículum es una forma de codificación en el contexto académico-universitario, donde el emisor y el receptor manejan la misma codificación-decodificación y el ruido se reduce bajo el criterio de la sanción social. Esto es especialmente evidente en los casos en los que se saca de su contexto, académicoinstitucional, y se reproduce-clona en formas metatextuales diferentes, se pone en Internet por ejemplo, donde las claves de lectura se reformulan y toman inesperados y curiosos giros. A principios de esta década una profesora de una prestigiosa universidad americana había hecho su tesis sobre el sistema económico alemán de posguerra, por indicaciones de su departamento colgó en la Web de su universidad su currículum, donde resaltaba no sólo su impecable vida académica, sino sus dos docenas de trabajos publicados en revistas de máximo nivel. Alguien lo vio de la televisión alemana, la famosa MRD, y se puso en comunicación con ella para que hiciera un par de comentarios al respecto de la crisis del Deutschebank, ella no sabía gran cosa pero aún así accedió por dar un punto de vista historicista, cuando fue presentada en antena se citaron algunos de sus trabajos y entonces sobrevinieron las protestas de algunos agentes sociales, que no sólo no dieron validez a sus palabras sino que no les parecía que el publicar en ciertas revistas la legitimara para opinar sobre la política económica de Alemania. Sin embargo, es evidente que sus colegas académicos en Alemania, que aparecían habitualmente en los medios de comunicación como expertos, publicaban en las mismas revistas que la profesora americana e, incluso, habían publicado juntos en varias ocasiones. En cualquier caso, más allá del criterio nacionalista que se escondía bajo determinadas críticas, el problema es que el currículum de la profesora en cuestión tenía una codificación que no podía ser entendida fuera del contexto académico y que el metatexto por el que se mostraba llamaba obviamente a una permanente confusión entre el saber y sus implicaciones de acción.

El currículum se normaliza, en consecuencia, porque se hace académico: se hace en la academia para y por la academia. En su sentido estricto el currículum vitae era la descripción de los pasos (steps) que tenía que pasar un individuo, en el mundo de los oficios de la Época Clásica, desde que entraba de aprendiz hasta que llegaba a maestro. El currículum era una guía frente a nuestro moderno currículum, que marca los diferentes pasos que el académico ha dado hasta llegar a un punto (el aquí y el ahora), la principal diferencia es que uno era impuesto y el otro es inducido. Pero esta diferencia es importante. Para ser Profesor Titular, establecido desde una acreditación-oposición, hay que haber dado unos pasos y se hacen en forma de ítems: estudio de la licenciatura en tal o cual sitio en tal y cual fecha, luego el doctorado, haber publicado y obviamente haber dado clases con anterioridad en tal y cual universidad. Pero estos ítems no están previamente marcados lo que les convierte en una suerte de azar y necesidad. En este sentido todo apunta a que es el sujeto el que aparentemente hace (crea con su trabajo) el currículum, cuando en realidad es casi seguro que dado el sentido, la orientación e, incluso, su funcionalidad es el documento el que crea lo que el sujeto es. Si esto lo ponemos en el contexto académico y lo relacionamos con la actividad de "ser" profesor de universidad, donde se reparte el tiempo en partes desiguales entre la docencia, la investigación, el aparato burocrático y la charla intranscendente con los compañeros, se puede comprender que una carrera académica es más el saber estar, que el saber hacer, y en última instancia una clara sintonización institucional (Morán 1995), que de alguna manera es el método más común para minimizar los riesgos del no poder-saber hacer (pensar) y, a la vez, de encontrar algún camino aparentemente coherente en el caótico proceso de hacer y mantener un currículum que de alguna manera lleve al sujeto hacia una "profesionalización" del ser universitario (Ferrerés 2001). 


\section{Haciendo carrera}

Las cátedras parecen el punto álgido y el blanco de la gran parte de las carreras académicas, aunque por algunas razones que sería largo de explicar la aspiración se ha quedado en la tristeza de la titularidad y un buen número de los profesores renuncia a la cátedra; en este caso es evidente que se puede decir con Goffamn (1997) que toda carrera comporta también una cierta carga de estigmatización. En cualquier caso, la cuestión es llegar y para ello se pide como requisito ser doctor, además de otros muchos más determinantes. Pero cuando alguien está haciendo la tesis doctoral no piensa que esto sea importante para ser catedrático. La relación entre un punto y otro, que están separados temporalmente en no menos de quince años, se hace las más de las veces inconexo y difícil de explicar. Además, la tesis doctoral no asegura ni de cerca poder llegar a iniciar una carrera académica. Se puede decir que todo currículum es una relación de los pasos dados pero a su vez no es algo que determine el siguiente paso. Esto es paradójico con las carreras académicas desde un punto de vista administrativo, donde parece ser que todo está previamente establecido, pero sólo a un nivel de requisitos de títulos, en ningún caso en cuanto al contenido y lo que resulta evidente a todas luces es que una carrera académica se plasma en un currículum según unos determinados contenidos, y los títulos son, si se atiende al proceso, secundarios. Este enorme nivel de paradoja exaspera a un buen número de jóvenes, y no tan jóvenes, que empiezan a dar sus primeros pasos en la carrera (Gewerc 2001). En líneas generales nuestros doctorandos viven de manera radical este nivel de paradoja, entre lo administrativo y lo académico: como tutores y directores les pedimos que publiquen y acudan a congresos, pero a su vez que terminen la tesis; ellos, como no podía ser de otra manera, preguntan constantemente para qué, pues cuando acuden a un congreso sin ser doctores son tratados como investigadores de segunda, por lo que sugieren centrarse en la tesis. Pero -porque cuando hablamos de la academia siempre hay un pero- es difícil de explicar que se trata de un otro nivel, el curricular, donde si bien la tesis es importante, incluso determinante, en una carrera académica no lo es menos el tener esos otros ítems, de donde obviamente la "humillación" padecida es parte de lo que se supone ha de pasarse. Obviamente que el inicio de una carrera académica requiere de un criterio de formación (Benedito y otros 2001), que es más un acoplamiento a las necesidades institucionales que cualquier otra cosa. No es de extrañar en este sentido que exista un principio de uso personal que se ampara en discursos de costo-beneficio para el currículum.

El currículum vitae de un académico es una serie de papeles que muestran sólo los logros certificados en forma estándar (5). Nada más. Quizás el currículum normalizado se convierte en un hecho casi universal y disciplinado del mundo funcionarial sobre la academia, y en realidad porque se trata de algo que el final da importancia al continente sobre el contenido, en otras palabras, a las muchas páginas por encima de lo que esas páginas digan. $\mathrm{Y}$, contrariamente a lo que pueda parecer, no digo esto con un afán moralizante, pues reconozco que de forma general detrás de un currículum "gordo" hay mucho tiempo, esfuerzo y trabajo, sino que digo que esta manera de hacer las cosas en los que prima la cantidad no es más que una de las múltiples vías y que no siempre es la más justa, representativa y funcional. De hecho, no es capaz de mostrar qué relación tienen los ítems entre sí, ni darnos una idea clara de las líneas, derivas y enfrentamientos del individuo a lo largo de sus años. Y todo porque no hemos conseguido hacer que diga los por qué. Aplicando algunas ideas de Deleuze y Guattari (1994) podemos decir al respecto que los conceptos e ideas, nunca se corresponden con una forma geométrica definida, ni caben del todo en un soporte físico. Hay que elegir y seleccionar, des-re-ligar (cortar y pegar) en un nuevo espacio: el de la superficie escriptórea, que, discreta e inerte, debe participar de una o más series de espacio-tiempo, para así cobrar estatus de registro en el currículum. Indagando en esto mismo podemos traer algunas de sus ideas, utilizadas para la idea de concepto, y observar que no hay un currículum simple, ya que todo él tiene múltiples componentes que lo definen. El currículum es consecuentemente una multiplicidad en si mismo, que tenderá al caos y que se ve ordenado al circunscribirse a un único universo que lo explique y que lo reabsorba. Todo ello crea una ilusión de repetición que de alguna manera reparte la realidad del sujeto en situaciones aparentemente nuevas, planteando su vida (vitae) como un devenir hacia los items que ha remarcado en su currículum y que de 
alguna manera guardan alguna relación, aun cuando sólo son solapamientos de una realidad más compleja. En efecto, se trata de un mapa vital que no responde a una cartografía real, muy por el contrario es sólo el dibujo del territorio de lo hecho en función de ciertos elementos que tienen que ser aplicados como la prueba de carga. Se podría afirmar que de alguna manera el currículum vitae es una ilusión biográfica que se queda en un documento pericial de la academia y que a todas luces parece negarse a tener vida.

Si entendemos el currículum vitae como una relación de hechos autoriales y su naturaleza es la de entenderse en un contexto académico este sólo puede ser entendido si implica más personas e instituciones que las que el proceso autorial puede abarcar. Siguiendo esta línea Janet Miller (2006) nos propone que incluso todo currículum es parte de una autobiografía a nivel mundo, donde las instituciones y los temas determinan la forma en que se negocia el estar académico. En este sentido y de forma general se puede decir que estamos ante la parte ingenua de la ilusión biográfica, tal cual la entiende Bourdieu (1994), ya que suponemos que un sujeto siempre será mucho más que aquello no sólo que puede relatar, sino poner en un documento tan social y socializante como es el currículum. En última instancia, podemos decir que el porqué de un currículum tiene que tener varios y diferentes frentes. Esta vía en la que el autor de aquello que dice el currículum vitae es importante e, incluso, determinante, sólo puede ser entendida en el contraste con otros. Esta es sin duda la primera característica de un currículum vitae, es siempre algo que conecta a un individuo con otros mundos, a veces ajenos a él. Lo que se muestra es el enorme ejercicio de interdependencia existente en los marcos académicos. Desde la investigación más sencilla, al más sutil y elaborado artículo, es siempre un entramado de redes, formas y conocimientos en varios sentidos, algunos de ellos, sin duda, muy paradójicos. De hecho, la inmensa mayoría de los artículos que un académico publica exige varios elementos que no siempre están en las manos de su autor.

Estos elementos son tanto de un orden objetivo como de sensaciones subjetivas. Un amigo me decía que él tiene más capacidad de publicar que de escribir, otro, si embargo, me comentaba que él tenía problemas para publicar, porque había pocos sitios donde le consideraban sus investigaciones y, un tercero, me explicaba que todo lo que publicaba formaba parte de encargos. Si partimos de que parte del currículum vitae, las publicaciones, son una de su piedras angulares tenemos que entenderlo en esa doble dimensión de lo objetivo/subjetivo. En última instancia, simplemente porque son reflejo de aquello que se produce en el espejo de la academia. Las publicaciones son al final un resultado, aunque se pongan como el resultado, y como tal tienden a concentrar algunos de los elementos que se suponen definitorios de todo currículum vitae. Toda publicación que se sitúa ante la academia utiliza una y no otra bibliografía, muestra algunas destrezas, recrea literariamente un experimento (cuando menos el del pensamiento en abstracto) y, sobre todo, ubica al autor en unos parámetros a veces comparativos y, consecuentemente, frente a otros, y las más de las veces a favor de conocimientos, paradigmas y miradas de su entorno académico inmediato.

Y si publicar es lo más importante de una carrera académica es normal que el currículum vitae le haga justicia, poniéndolo en lugar central de todo su discurso. Esto crea, por un lado, un efecto sociológico directo: las publicaciones de un currículum vitae tienen vida propia, una vida social independizada de su autor al menos como parte de las memorias institucionales y/o mediáticos. Por otro lado, entendemos que no es sólo la biblioteconomía quién toma al impreso como realidad, es, sobre todo, su enorme capacidad para ser elementos con capacidad. Porque prácticamente cualquiera otra parte de un currículum vitae está en un momento instituyente, en simple construcción. De hecho, a las universidades les preocupa sobremanera que sus profesores no publiquen todo lo que puedan, lo que generalmente alientan con un discurso basado en la excelencia, aunque eso no significa que se preocupen de poner las condiciones, pues la historia institucional está hecha de estos elementos objetivos que permiten la comparación. Las publicaciones, ahora más con el sistema de revistas por referato, algo adquirido del régimen universitario norteamericano, parecen el colmo de la objetividad institucional y por extensión de los profesores. Incluso puede decirse que las publicaciones son junto con el trabajo para-burocrático e institucional aquello que marca la diferencia de un currículum con otro y de universidad con otra, una coincidencia de intereses, entre el sujeto y la institución, que nos permite observar con claridad lo real que es la academia. Pocas instituciones sociales tendrán un nivel de integración tan fuerte con los 
sujetos que las habitan, hasta el punto de que ya no sólo se trata de un elemento que se defina por un aparato político mancomunado, sino por el sistema de retos a nivel global (Carrizo 2004), lo que tiene mucho que ver con las nuevas formas de totalitarismo socio-institucional.

\section{El currículum nominativo}

Pensemos por un momento el currículum vitae como un todo. Nos encontramos en consecuencia ante una representación estética de los logros de una carrera académica. Esto marca dos planos: uno vertical, que relaciona el currículum vitae con lo social, con lo académico, y otro horizontal, que es el discurso que plantea. $Y$ mientras que de manera vertical se mantiene gracias a una fuerza centrífuga, que tiende a resaltar más lo conseguido por el autor en la academia, en su horizontalidad es centrípeta, tendiendo a concentrar lo que expone en función de una única unidad o, dicho de manera más tecnológica, a ser un único del individuo. De ahí que el discurso del currículum vitae sea plantear que de alguna manera tras él se encuentra el genio: el de ser uno único. Otra cosa bien diferente es que la academia luego lo permita o que lo obvie o que simplemente lo integre. Pero como representación de alguna manera tiene que plantear que existe un tono de genialidad en el firmante, pero que se hace de alguna manera en función y armonía con el todo académico, quizás porque la academia, a su vez, se presente como la reunión de genios, pero eso es otra historia.

La paradoja está en que la academia no puede presentarse dentro de la teoría de sistemas, en última instancia porque es una estructura de poder que se autoproclama no peligrosa, mientras que el currículum vitae es claramente un proceso sinérgico, donde la integración de los diferentes elementos da como resultado algo más grande que la simple suma de éstos. Es lo que lo baja al territorio de lo humano y hace del currículum, irónicamente, democrático, pues si se tratara de una representación únicamente bajo la idea de la genialidad bastaría con tener una parte, por insignificante que parezca, para darse cuenta de ello. Y, sin embargo, se trata de un conjunto de elementos que sólo en su conjunto representan que la genialidad es la academia. Obviamente como toda paradoja el currículum tensiona la realidad entre lo individual y lo social, poniendo a quien representa en el juego de las representaciones sociales y, por lo tanto, la academia no es sólo el receptor del currículum vitae es, sobre todo, su creador, dejando que sea el individuo quien a lo más lo ejecuta. Claramente hablamos de lo desconcertante que es entender que existe una cierta idea de creacionismo y no poco de determinismo sociológico (Zabalza 1998). En realidad gran parte de esto tendría otra lectura si nos plantemos el enorme ejercicio de poder que plantea la institución universitaria.

Es evidente que el currículum vitae normalizado plantea, por un lado, qué se ha recibido, y de qué manera se ha hecho, y, por otro, qué es lo que se ha devuelto en forma de conocimiento. En cuanto enmarcado en una teoría general del conocimiento recrea una determinada dinámica vital con respecto a la disciplina académica que, objetivamente parece, es censurable. El currículum planteado de esta manera es siempre un discurso en positivo: referencia sólo y únicamente los logros y obvia los fracasos, el rechazo, la negación y la imposibilidad. El currículum vitae, dicho así, es una realidad vital dinámica de miradas positivas -de ahí que sea una representación en su sentido semiótico más clásico-. La tendencia básica a creer, mientras se está académicamente activo, que el currículum vitae crece (y engorda), como si tuviera una dinámica tan humana, vital, como propia, es un hecho físicamente positivo. Porque en realidad todo currículum es sólo o parte de un proceso o, en su defecto, la culminación de este. De ahí otra de sus paradojas: su crecimiento es sólo una imposibilidad en sí mismo o, en el mejor de los casos, un futurible que asume el permanente cambio de las cosas de manera independiente. Si el currículum vitae es proclive a crecer es porque, de alguna manera, deja entrever que tiene posibilidades reales de cambiar, acaso de crecer según una determinada mecánica académica, pero acaso también adaptándose de manera no lineal. Por su propia dinámica, pero también porque es un documento funcional y útil, el currículum tiende a presentar a ese alguien de manera definitoria como algo definitivo y, si no completa, al menos completada.

Por eso mismo el currículum vitae crece sobre todo discursivamente, mostrando tanto como esconde, 
guiando por un determinado camino y no por otro, retorizando con sus apartados una línea determinada de trabajo, que en realidad es sólo de acción. En última instancia, un currículum vitae muestra el trabajo en forma de logro y permite que el individuo sea un ser único, irrepetible, en función de una labor. Se determina así una representación contemporánea de la definición de "sujeto", incluso de ciudadano, por medio de la adscripción a una determinada esfera laboral. Si el trabajo es la esencia del sujeto contemporáneo el currículum vitae es su forma de validación. Más a más cuando el trabajo es dentro de la academia, ese espacio-tiempo que se autodefine por su labor en pro del conocimiento. Pero no se trata de un simple trabajo se trata de representar la capacidad de acción en el pensamiento, una especie de contradicción que se resuelve al dejar que sea el currículum el que tome su vida propia en función de otros intereses. En este sentido lo que se muestra tiene que ser parte de un pacto. Dicho de otra manera, todo currículum por particular que parezca es siempre un pacto previo en los esquemas de la academia (véase también las ideas paralelas al respecto de Popkewitz 2010). Y así el currículum vitae de un candidato a una plaza de profesor del nivel más bajo -dicho de una manera arqueológica, que no de clase/status- mostrará, sobre todo, su formación y las habilidades adquiridas. Mientras que el de un profesor con un par de décadas de experiencia se esperará su capacidad de gestión, sus publicaciones y su capacidad en las relaciones inter-universitarias. El currículum vitae parecerá, de esta manera, que tiene una cierta lógica de ascenso socio-académico enmarcado en un contexto socio-laboral.

El currículum vitae, así, está pactado, reflejando en cada momento lo que se espera de cada cual: tan sospechoso sería un joven profesor de treinta años con cuatro libros como uno de cincuenta que no tuviera reflejadas, como mínimo, tres invitaciones a otras universidades de Estados Unidos o Europa. Hablamos, en consecuencia, de discursos confirmativos que tienden a la afirmación del sentido dinámico de los miembros de una academia. Y, visto así, un currículum nunca crece, es sólo una reseña de las obligaciones que se han ido cumpliendo. Es un sistema de necesidades que se cubren en cada momento y que muestran al individuo en función de ellas. El currículum vitae, consecuentemente, no se puede hacer, solo ir afirmando en sus etapas, que previamente determinadas por lo ejercicios académicos se censan según esos parámetros. Y así ocurre cuando se pide que los currículum vitae sean evaluados desde fuera de estos criterios normalizadores de la academia: se corre el riesgo de que no se reconozca que el currículum se realiza en unas etapas, que subjetivamente son simples hitos, exógenos al individuo y no simples logros para el conocimiento. Cada entrada de las muchas que forma un currículum es un simple hito que se entiende como un detalle en planteamiento dinámico, ya que la sinergia la marca la academia. El currículum vitae, en última instancia, sólo quiere ser una representación de lo posible en el contexto académico.

Al hilo de todo esto es importante reseñar que por definición todo currículum es provisional y contextual y tiende a mostrar más de lo que en realidad es. Se trata en cierta medida de un ejercicio de maximización de la realidad académica. No podría ser de otra manera, ya que en todo currículum está creado para representar a la vez que tiene que ser especialmente operativo, digamos funcional. Al no trabajar como un dispositivo en vacío, sino en ese contexto académico concreto, su principal función es el de validar la enorme endogamia del sistema. En primer lugar porque todo trabajo universitario, por lo menos al principio, se tiene que hacer en un contexto de cierta proximidad y, segundo, porque al ser representativo de ese contexto prácticamente es exclusivo para y con ese espacio predefinido. Una redundancia propia de los sistemas con fuerte carga endogámica. Si pensamos además que la inmensa mayoría de las universidades del mundo tienen sistemas, líneas predefinidas de investigación y recursos materiales y humanos muy limitados, tanto la creación del currículum como su presentación estarán sujetos, cuando no anclados, a una realidad muy concreta, lo que tiene un único sentido: la endogamia. Por eso mismo cuando los poderes del Estado, a través de sus ministerios y secretarías generales, se plantean acabar con esto, como si se tratara de un lacra social, no entienden que el problema parte del mismo sitio en que ellos sitúan a los universitarios con sus políticas de unificación y homologación de la docencia y la investigación.

El currículum como documento de la representación académica muestra a los individuos en un cierto contexto de lo social, en un área que le hace válido en un determinado escenario. Por eso mismo el currículum tiene algo de guión teatral a la inversa, pone por escrito el performance académico, el enorme juego, casi permanente, de la ritualidad de la vida universitaria. Una teatralidad de escenarios poco 
cambiantes donde siempre se establece un relación entre maestros y discípulos en un marco de tradiciones (de investigación) y continuidades de docencia. El currículum muestra que el docente de hoy fue alumno de alguien en el pasado y que de alguna manera está capacitado para continuar el proceso de manera cíclica, pero también, como se hace en la linealidad de los paradigmas políticos y académicos más globales. Obviamente la endogamia es detestable, por un lado, porque rompe con el sistema libertad e igualdad en el acceso a las oportunidades, y por otro, porque crea un arterosclerosis sistémica.

Por eso mismo podemos decir que la universidad se niega, al menos en aquellos lugares alejados de la educación y la investigación no esta reglada, y donde resulta determinante el por qué y el cómo del currículum vitae, a mantener un aparato curricular, una suerte de guía de los estudios formales que se han de pasar para llegar a validar tal o cual paso dentro de la academia. Y no es ni por una falta de control de que se ha de tener o no, pues en última instancia, ciertos títulos y requisitos son imprescindibles según el qué. Para ser profesor titular en España, por ejemplo, es necesario estar en posesión del título de doctor, tener una habilitación nacional, haber dado unos tantos años de clase, ser ciudadano de la Unión Europea y no haber sido separado de la administración pública por razones penales o civiles. Pero obviamente hace falta algo más: un determinado currículo que remarque que el profesor tiene determinada experiencia, publicaciones y reconociendo disciplinar. Por igual, es evidente que el alejamiento de las posiciones curriculares está en relación con un cierto discurso de la libertad y la autonomía imperante en todos los niveles de la vida universitaria. Sin duda, este discurso, sumado a las posiciones de individualidad planteadas desde el currículum, crea un sujeto que mantendrá sus posiciones por encima de casi cualquier cosa, incluso por encima de cualquier posicionamiento moral. Es verdad que detrás del currículum se encuentra una mirada de la academia, una carrera y obviamente un sistema de representaciones de las posiciones éticas, en cuanto que es una política social que le sirve de contexto, y los valores adquiridos.

Pero tanto los elementos formales de un currículum, cuanto más el propio discurso de la autonomía y la libertad, están prefijados por el criterio disciplinar. $Y$ en este sentido, la universidad se vale de los ejercicios normativos de la razón y la ciencia para crear una ambiente ecológico-político, que si bien no remarca el aparato curricular es evidente que pone toda la carga en el llamado currículum oculto: todas esas cosas que no están en el apartado formal, pero que establecen las direcciones, miradas y valores del grupo mayoritariamente dominante (Apple 1979; Apple, Beane 1997; Beane 2005). En este sentido es evidente que no es que la universidad tenga un proceso de ocultamiento de sus dispositivos, simplemente que oculta tras el velo de la razón sus posiciones políticas de dominación. En última instancia la universidad como centro de la academia no sólo establece el cómo se hace tal o cual cosa y como esta ha de estar en el currículum, sino que también se dedica a juzgar si es correcto y la calidad de los elementos. Se entenderá que una institución que se erige como juez y parte sólo puede ser clasificada como un lugar políticamente totalitario. Por otro lado sólo recordar que la idea de calidad del currículum está en relación con una idea más general de "deber social" por parte de la institución (Rico y otros 2001), que se plantea una eficacia que ralla, en el mejor de los casos con el absurdo y políticamente con el fascismo. Si a esto le sumamos que gran parte de los discursos en torno a la libertad y la autonomía se quedan en un trabajo generalmente mal pagado, lleno de burocracia y control administrativo, cuando no en la enorme frustración de sólo dedicarse a los alumnos de licenciatura, sin posibilidades de investigar, con unos recursos demasiado recortados y en un estado permanente de alerta por los controles y evaluaciones de las agencias gubernamentales, que en el fondo crean sistemas de comparación inter-pares que minan el ya de por si devaluado prestigio social de trabajar en el medio universitario.

Nadie puede dudar que la universidad era un lugar de cierta reclusión utópica hasta que llego el control del Estado y la creación de la idea generalizada del curricúlum normalizado. En este sentido se sumo a la idea de la liberta de cátedra el de la autonomía universitaria. Evidentemente todo apuntaba a que la nueva clase de académicos no tendría que velar por que se dieran criterios de libertad, sino cuidar por la autonomía. Es decir, que la libertad, en cuanto valor que se basa, sobre todo, en no dar explicaciones de lo hecho, aunque ciertamente nunca se ha podido hacer lo que de verdad se quiera, se abandono en función del criterio crematístico. Y los académicos se han ido convirtiendo poco a poco en gestores, en una nueva clase social de burócratas, que gestionan el saber-poder. Por eso mismo es tan importante el 
currículum, porque es la forma más elaborada de representar los niveles de gestión del conocimiento y cuánto ha sido la sujeción al poder social de la institución. Digamos que hace visible la parte más evidente de la disciplina académica. Por eso, también, se recrea a sí mismo como un documento de una cierta transparencia, incluso como algo público que no pocos creen una suerte de carta de autopresentación ante la sociedad global.

Para Bateson (1985) los documentos tienden a la redundancia, la repetición permanente de si mismos y mostrarse como sistemas de orden y control, en este sentido todo currículum como documento tiende a repetirse y a manifestarse dentro de un contexto preciso, de enorme racionalidad, normalidad y bondad, en última instancia es un documento producido por y para la academia y como tal trata de imponerse en esos valores. Pero que nos encontremos ante un documento tan aparentemente alejado de todos aquellos elementos sociales ambiguos o negativos le da un valor demasiado contextual como para no entender que algo tiene de oculto, de elemento no revelado. No ya sólo, que también, porque es inminentemente positivo y plásticamente lineal, sino porque muestra únicamente aquello que parece esta en un guión perfomativo, de pasos rituales hacia un escala de valores preafirmada y asimilada como la única posible. El currículum, así, parece cerrarse sobre si mismo, más porque su punto álgido, las publicaciones, son a su vez documentos de lo hecho, de lo que es pura acción, y, consecuentemente muestra todo la potencialidad de la realidad. Pero como ocurre con la institución que lo promociona, lo importante parece una vez más que todo parece quedar expuesto de manera positiva, lineal y con bondad, dejando los sentimientos, los valores, el esfuerzo y el sufrimiento fuera del terreno de lo hecho. Quizás por ello prolifera el currículum donde los méritos conseguidos en los puestos académicos de gestión sobresalen, porque son, por encima de cualquier otra consideración, pura acción anti-sentimental y "únicamente" entrega institucional, digamos que son los hechos por encima de reflexión.

\section{El currículum como política}

Como un aquí y ahora total el currículum vitae es un cronotropo, marcando un momento de fuerza en el espacio y el tiempo. Y si quiere dar lugar a un tipo de contrato es porque en su interior está la intencionalidad de lo posible, pero también de su contrario, de aquello que es únicamente lo posible. En última instancia, todo currículum vitae es un juego de evocaciones de la desmemoria, de aquello que no quiere reseñar, como si el fracaso o el esfuerzo o las trampas no existieran. De alguna manera un currículum será un ejercicio para la academia, en su sentido de negar la poli-dimensionalidad de lo humano, de marcar sentidos que obvian el origen grotesco de la realidad que le es ajena. El mejor currículum vitae será aquel que por definición lo dé todo por la academia, descarnando al individuo que deja de lado cualquier formulación del ser como un todo. De hecho, el currículum es un reconocimiento implícito de un juego de posibilidades disciplinantes relacionadas con la actuación política del poder. Un poder, el de la academia, que es líquido y toma la forma del continente. En este caso el currículum vitae es evidentemente una representación de una sumisión, un plegamiento al poder, quizás absoluto, de aquellos que censitivamente establecen un juego de validaciones esquemáticas.

En efecto, el currículum vitae sólo se entiende en el juego político del fractal, siendo la repetición permanente de una constante, donde la frontera entre los diversos elementos son sólo parte de un discurso. Un discurso inminentemente político, que impone algún tipo de acción, de creación permanente de un mismo elemento que tiene que estar prefijado, quizás reconocido, pero que se establece en los márgenes del propio documento. El currículum, así, es una suerte de negación de lo pensado, es sólo un criterio de lo hecho. Seguramente la clave sería su destino, en la medida que tiene que ser funcional, emplearse, digamos tiene que socializarse, y como tal se establece como un mecanismo de una maquinaría que nunca permite trabajar en vacío -en este caso, en lo abstracto del pensamiento-. Un componente que toma la forma de un relé (relay), un dispositivo mecánico que permite ser intercambiable, permutable y mejorable, haciendo de interruptor de la realidad del sistema. En última instancia, el currículum vitae es un documento dinámico que establece el dispositivo de las representaciones académicas. La propuesta de que éste no tiene un final se hace en la marcha constante del tiempo, y que es mejorable, siempre se puede sumar un grado de mayor eficacia en la 
representación, introduce al mecanismo en una posición política de acción y no del simple ejercicio de pensamiento. Incluso podríamos creer que todo currículum es sólo lo hecho, nunca lo que se pensó. En este sentido, no deja lugar al sueño -quizás al ensueño, a la material aspiración-, a lo imaginado, incluso a lo posibilitado y sólo hace referencia al futuro como algo posible, negando una vez más el devenir de lo humano.

Consecuentemente el currículum vitae mantiene, como texto documental, pero también porque forma del contexto académico, una lógica de mensaje -de ahí su posible lectura, interpretación e intercomparación, con un emisor, un receptor, su forma y consiguiente ruido. Pero lo que le define es el juego que se establece entre el emisor y el receptor como un metatexto: un conformador de la dimensión del texto que tiene una lógica, simbólica, diferente de la que tiene el contenido, resolviendo en unos casos una funcionalidad y, en otros, un mensaje implícito y textual. Pero al no existir la posibilidad de mostrar lo hecho de manera positiva no hay otra posibilidad que el regreso como simulacro. La línea, una vez marcada, sólo permite creer en los futuribles: en alguna posibilidad de que la academia no estableciera, no creara, o dejara otros. El currículum leído como un metatexto tiene que mostrar las fisuras del poder, pero no para introducir la cuña que la rompería en mil pedazos, sino para cerrarlas, para hacerse más compacta, más concreta. Todo currículum niega la posibilidad de soñar y tiene que mostrar la adscripción política, la ósmosis académica en el espacio y en el tiempo (6). Sólo eso y nada más que eso.

En definitiva, el currículum vitae homogeniza no sólo su contenido, que también, sino también al individuo que lo crea. Dando importancia a todo por igual y "fiándose" de que el lector lo sepa interpretary desentrañar, buscando el detalle donde pueda estar lo único, la genialidad, la chispa que provoque una diferencia con otros currículum vitae. Vana esperanza de aquello que sólo es un documento de la adscripción disciplinar a la academia. El sujeto disuelto en su currículum sólo puede esperar que se parezca a lo creado por la academia, el resto es acaso desesperanza. Pero al negar la categoría de lo personal, el ejercicio de su lectura es una suerte de mirada cientifista que disecciona y escudriña entre las vísceras hasta constatar que no se tiene alma, personalidad, unidad y sólo simbiosis con el planteamiento de la academia. La ingenuidad de algunos reside en creer que existe algo que vincule el currículum vitae y el sujeto, cuando es sólo un discurso de la representación, una validación a lo más, nunca lo que es, sólo una propuesta de la acción, a lo más una negación de la corporalidad, del pensamiento y del futuro. Dorothy Smith $(1986,1990,1999,2005)$ ha examinado el papel de la documentación en la burocracia y, con ella, en la conformación del Estado moderno, según ella Estamos supeditados a diario, mucho más de lo que suele pensarse, a un proceso de inscripción, a necesidad de contar con signos impresos o escritos y de obrar de acuerdo al dictado de ellos. Y, así, las formas de organización social mediatizadas por documentos y textos son dependientes de la aptitud del documento para materializar y preservar un conjunto definido de mensajes/palabras que es independiente de su historicidad local, de aquello que se puede dar por vivida. Plasmado el significado en el texto, en su forma material permanente, extrae su sentido de los procesos de su construcción transitoria y de las vicisitudes de su elaboración. Según ella en las sociedades no alfabetizadas la concentración del significado en formas no supeditadas a la temporalidad recaía en el ritual, el megalito y la imagen, mientras que en nuestros días los modos extratemporales de significado se crean en forma escrita o impresa, siendo formas semi-permanentes que se tornan rutinarias y triviales, transformando nuestras relaciones con el lenguaje y el significado, y la relación entre ambos. En ausencia de oradores hablan los textos. Entonces el significado es aislado del contexto local de interpretación: el "mismo" significado, puede así repetirse a la vez en una multiplicidad de situaciones sociales y temporales diferentes. El aparato de gobierno de las sociedades industrializadas está organizado en todos sus aspectos por formas de gobierno mediatizadas por documentos, por textos y discursos. Es evidente que desde este punto de vista el currículum cumple una función que va más allá del simple planteamiento académico, haciéndose patente de su juego como creador de discurso, un discurso en el orden de lo político.

En Europa en general hay que pasar una serie de pruebas de carácter oral para acceder a los puestos de profesor permanente, algo parecido ocurre en Estados Unidos con la entrevista personal, de donde destaca dos partes, en la primera hay que hacer una exposición razonada del currículum y en la segunda una exposición de una investigación original. No es este el lugar de pensar este sistema que trae de cabeza a los responsables de la administración pública, dado el enorme carácter endogámico y 
excluyente y privativo que comporta, donde evidentemente se perfila un sistema de reclutamiento privativo inter-pares que mantiene un sistema autónomo con respecto a prácticamente cualquier otro poder institucional y que está fuera del control del Estado -olvidan los críticos de esta manera casi medieval de actuar que gran parte del cuerpo de profesores que evalúan son ese momento la más alta representación de los valores del Estado Nación-. Lo que ahora hay que destacar es qué ocurre cuando un documento que representa el quehacer académico se expone públicamente, dando la oportunidad de crear el discurso valorativo que la "frialdad" del documento impide realizar. Tenemos que entender en primer lugar que la exposición pública de los hechos particulares pertenece al ámbito de las relaciones políticas, a ese espacio social donde un grupo se da unas normas que acata, pero también fuerza, para llegar a un mundo de lo posible. En este sentido, la exposición del currículum es un descarnamiento social no exento de un dolor que en no pocos casos tiene algo entre caníbal y mucho de esa crueldad social que le es propia a los sistemas de reclutamiento por adscripción.

Como en todo discurso expositivo donde las partes no se encuentran en el mismo nivel la tendencia es a recrear no lo que es obvio de por sí en el propio currículum sino a justificar todo aquello que de alguna manera es obvio a nivel académico, forzando la maquinaria de lo formal. Es lo que Rene Lourau (1970) llama la creación de la trasversalidad: el apelar a una norma que este por encima de aquellos que están por encima del evaluador, con la creencia en que el criterio institucional está por encima de cualquier otra consideración. De lo que se trata es de demostrar la enorme "normalidad" del currículum, sabiendo de antemano que cuando uno se presenta a este tipo de pruebas tiene que cumplirse estrictamente la parte formal y que sólo queda apelar a los criterios de asimilación institucional. En efecto, el currículum, más a más cuando se expone públicamente, dado el nivel de retórica que la situación requiere, por encima de cualquier otra consideración lo que tiene que demostrar es un valía, un adquisición de unos conocimientos, pero de manera oculta tiene que ser un documento que deje claro la asimilación incondicional a una determinada disciplina, la capacidad de homogenización institucional. No se trata sólo de un reducionismo por mi parte, sino de entender que las múltiples maneras de ser profesor provienen en general del entendimiento dialéctico y no dialógico entre el sujeto y la realidad social, lo que lleva a un mirada que considera al profesor universitario eso que Amparo Martínez (1997) llama el "practico reflexivo". Es decir, un tipo particular de profesional que parte de una práctica para superarla por medio de la búsqueda de soluciones de los problemas que ha preestablecido. En este sentido entender el currículum como elemento de la práctica profesional es también proponerlo en un contexto de microfísica del poder, en la medida que representa las soluciones de orden práctico de los sujetos a un medio, sobrevalorado en la reflexión, que se reduce a un sistema altamente mecánizado y que es todo un ejercicio de la voluntad del poder.

Se puede afirmar que dado el "nuevo" estado de las cosas en las universidades, con sus agencias de evaluación, sus criterios de eficacia económica, su preocupación por la implementación de un saber aplicado, el descarado chantaje a los académicos para que entren en juegos de comparación y la radicalización de la institucionalización de una mirada de la relación entre profesores y alumno de manera clientelar y tendente a jugar sólo un papel como parte de la sociedad del ocio, es evidente que el mejor currículum es aquel que tiene un fuerte contenido en la gestión universitaria. Esa es la resolución de la paradoja del currículum vitae cuando plantea donde está el encuentro entre la representación del conocimiento, su formación, sus aportaciones y la biografía del individuo: en cuantos puestos de gestión universitaria ha desempeñado. Porque aquí no se puede llamar a engaño ni a sospecha, porque no es importante si coincide las aportaciones del currículum con la edad y biografía del individuo, sino que la gestión está bajo otros órdenes, otros sistemas, de confianza, de poder, de prestigio y ambición que remarcan gran parte de la diferencia entre los buenos y malos currículum. En última instancia toda gestión universitaria se mueve en órdenes correspondientes a ejercicios sociales éticos, burocráticos, que imponen una mirada moral, generalmente muy maniquea de la realidad. En última instancia hacer un currículum normalizado es el primer paso de la gestión que se impone en la universidad como norma estándar de conocimiento. Es evidente que gran parte de la construcción de una vida académica está relacionada con el aprendizaje base de qué ha de tener en cada momento un currículum y es importante a un nivel académico que se sepa poner cada cosa en su lugar $y$, a la vez, que se construyan productos específicos para cada apartado. La vieja, por pasada y utópica, idea de que el currículum vitae son los pasos dados a lo largo de una vida académica, ha dado paso al currículum normalizado, donde lo que se 
prima es la representación funcional y efectista de la gestión de algún tipo de saber, de algún tipo de poder.

\section{Notas}

1. Que en la mayoría de los casos las novelas se centren en departamentos de literatura no sólo es porque de ahí provienen gran parte de estos escritores, sino que entre otros motivos porque se supone lo que es mucho suponer- que son lugares donde las normas estarían mucho más relativizadas que en un departamento de ciencias o ingeniería, lo que a la larga conlleva mucha más tensión dramática y, consecuentemente, elementos de fabulación.

2. Una primera versión de las ideas contenidas en este artículo las puse junto a Matilde Peinado (Anta; Peinado 2009: 401-432). En cualquier caso, e independientemente del agradecimiento a los relevantes aportes de la doctora Peinado, yo lo entiendo como parte de un análisis mayor donde se contextualiza otro de mis trabajos (Anta 2011).

3. En cualquier caso estoy con Mariano Urraco Solanilla (2008) cuando plantea que los nuevos escenarios de la investigación etnográfica no son tan nuevos como parcen a la vez que mucho de todo esto es poner a prueba viejas herramientas y nuevos usos de nuestras ideas.

4. No quiero entrar en la discusión histórica, que ahora me parece poco relevante, por lo que sólo recuerdo que el currículum vitae que ahora está normalizado es un documento que prácticamente no ha variado desde mediados del siglo XIX y que está asociado a un determinado criterio científico positivista y a la enorme jerarquización de las universidades bajo el modelo académico prusiano. Las palabras "carrera" y currículum tienen una etimología común, ambas provienen de la voz latina currere (correr), referida a competir dentro de una pista, cuya implicancia pedagógica es la del disciplinamiento en clases, según una realidad que es a la vez establecida y definida por el currículum (Goodson 2000: 59-60). Según el Oxford English Dictionary el primer Currículum fue programado en Glasgow en 1663.

5. El currículum vitae objetivo se trocea en siete partes básicas que lo hacen normalizado:

- 1: Datos personales (nombre, dirección, estado civil, edad y otros pequeños datos de adscripción).

- 2: Estudios cursados, premios, becas y otros méritos docentes y de investigación.

- 3: Experiencia laboral.

- 4: Publicaciones.

- 5: Presentaciones públicas en congreso, conferencias...

- 6: Proyectos de investigación y ayudas.

- 7: Otros cargos administrativos, cursos, informes...

6. Si de alguna manera cabe lo anecdótico en este trabajo sólo recordar que mi currículum vitae no soy yo -un yo adscrito y dicente-, en última instancia porque toda mi obra tiene vida propia, primero, porque publico, doy clases y me comunico donde debo, donde puedo y prácticamente nunca donde quiero, segundo, porque todo esto está en manos de lectores con diferentes sensibilidades y, por último, porque no todo tiene la misión de la expresividad o, en su defecto, de engrandecer mi ego, sino simplemente la de adscribirme a la política de mi academia. Una resignación que sólo se entiende desde el hondo dolor de la disolución. 


\section{Bibliografía}

Anta Félez, José-Luis

2011 "Espacio, tiempo y encuentro. Etnografía del lugar universitario", Gazeta de Antropología, 27 (2), artículo 26.

Anta Félez, José-Luis (y Matilde Peinado)

2009 "El curriculum vitae. Descripción densa de la representación académica", en René Pedroza y Carlos E. Massé (coords.), Educación y universidad desde la complejidad en la globalización. México, Porrua, Universidad Autónoma del Estado de México: 401-432

Apple, Michael W.

1979 Ideología y currículum. Madrid, Akal.

Apple, Michael W. (y James A. Beane)

1997 Escuelas democráticas. Madrid, Morata.

Bateson, Gregory

1972 Pasos hacia una ecología de la mente. Buenos Aires, Carlos Lohlé, 1985

Beane, James A.

2005 La integración del currículum. Madrid, Morata.

Benedito, Vicente (y Francisco Imbernón y Beatriz Félez)

2001 "Necesidades y propuestas de formación del profesorado novel de la Universidad de Barcelona", Profesorado. Revista de Currículum y formación del profesorado, 5, 2.

Bourdieu, Pierre

1994 Raisons pratiques. Sur la théorie de l'action. Paris, Seuil.

Carrizo, Luis

2004 “Producción de conocimiento y políticas públicas", Reencuentro, 40: 89-100.

Ferrerés Pavía, Vicente S.

2001 "El desarrollo profesional del profesorado universitario: Circunstancias, problemas y propuestas", Profesorado. Revista de Currículum y formación del profesorado, 5, 2.

Gewerc, Adriana

2001 "Identidad profesional y trayectoria en la universidad", Profesorado. Revista de Currículum y formación del profesorado, 5, 2.

Goffman, Erving

1961 Internados. Ensayos sobre la situación de los enfermos mentales. Madrid, Buenos Aires, Murguía, Amorrortu, 1987.

Goodson, Ivor F.

2000 El cambio en el currículum. Barcelona, Octaedro.

Deleuze, Gilles (y Felix Guattari)

1980 Mil mesetas. Esquizofrenia y capitalismo. Valencia, Pre-Textos, 1994. 


\section{Lourau, René}

1970 El análisis institucional. Buenos Aires, Amorrortu.

Martínez Sánchez, Amparo

1997 "El profesorado y la reflexión sobre la práctica", Profesorado. Revista de Currículum y formación del profesorado, 1, 2: 9-21.

Miller, Janet L.

2006 "Curriculum Studies and Transnational Flows and Mobilities: Feminist Autobiographical Perspectives", Transnational Curriculum Inquiry, 3, 2.

Morán Oviedo, Porfirio

1995 La docencia como actividad profesional. México, Gernika.

Popkewitz, Thomas S.

2010 "Los estudios curriculares y la historia del presente", Profesorado. Revista de Currículum y formación del profesorado, 14, 1.

Rico, Luis (y Sylvia Defior, Antonio Sánchez y Moisés Coriat)

2001 "Calidad de la enseñanza en la Universidad de Granada", Profesorado. Revista de Currículum y formación del profesorado, 5, 2.

Smith, Dorothy E.

1986 "Institutional Ethnography: A Feminist Method", Resource for Feminist Research, 15: 6-13.

1990 Texts, facts, and femininity: Exploring the relations of ruling. Londres, Routledge.

1999 Writing the social: Critique, theory, and investigations. Toronto, University of Toronto Press.

2005 Institutional ethnography: a sociology for people. Walnut Creek, CA, AltaMira Press.

Urraco Solanilla, Mariano

2008 "Cuando despertó... la tienda de campaña era una aldea virtual (y global). De lo novedoso y lo que no lo es tanto. Reflexiones en torno a la 'etnografía virtual'”, Gazeta de Antropología, 2008, 24 (2), artículo 42.

Zabalza, Miguel Ángel

1998 "De la genealogía a la biografía: ¿qué ha pasado con la didáctica en estos últimos 25 años?", Profesorado. Revista de Currículum y formación del profesorado, 2, 2. 